\title{
Titanium Dioxide Nanofibers and Microparticles Containing Nickel Nanoparticles
}

\author{
Faheem A. Sheikh, ${ }^{1}$ Javier Macossay, ${ }^{1}$ Muzafar A. Kanjwal, ${ }^{2}$ Abdalla Abdal-hay, ${ }^{3,4}$ \\ Mudasir A. Tantry, ${ }^{5}$ and Hern Kim ${ }^{6}$ \\ ${ }^{1}$ Department of Chemistry, University of Texas-Pan American, Edinburg, TX 78539, USA \\ ${ }^{2}$ DTU Food, Technical University of Denmark, Soltofts Plads, Building 2272800 Kgs. Lyngby, Denmark \\ ${ }^{3}$ Department of Bio and Nano System Engineering, College of Engineering, Chonbuk National University, \\ Jeonju 561-756, Republic of Korea \\ ${ }^{4}$ Department of Mechanical Design and Materials Engineering, Chonbuk National University, Jeonju 561-756, Republic of Korea \\ ${ }^{5}$ National Center for Natural Products Research, Research Institute of Pharmaceutical Sciences, School of Pharmacy, \\ The University of Mississippi, Oxford, MS 38677, USA \\ ${ }^{6}$ Department of Environmental Engineering and Biotechnology, Energy \& Environment Fusion Technology Center, Myongji University, \\ Kyonggi-do, Yongin 449-728, Republic of Korea
}

Correspondence should be addressed to Faheem A. Sheikh, faheem99in@yahoo.com and Hern Kim, hernkim@mju.ac.kr

Received 30 September 2012; Accepted 18 October 2012

Academic Editors: J. Bai, G. Dzhardimalieva, T. Peijs, and X. Sun

Copyright ( 2012 Faheem A. Sheikh et al. This is an open access article distributed under the Creative Commons Attribution License, which permits unrestricted use, distribution, and reproduction in any medium, provided the original work is properly cited.

\begin{abstract}
The present study reports on the introduction of various nanocatalysts containing nickel (Ni) nanoparticles (NPs) embedded within $\mathrm{TiO}_{2}$ nanofibers and $\mathrm{TiO}_{2}$ microparticles. Typically, a sol-gel consisting of titanium isopropoxide and Ni NPs was prepared to produce $\mathrm{TiO}_{2}$ nanofibers by the electrospinning process. Similarly, $\mathrm{TiO}_{2}$ microparticles containing Ni were prepared using a sol-gel syntheses process. The resultant structures were studied by SEM analyses, which confirmed well-obtained nanofibers and microparticles. Further, the XRD results demonstrated the crystalline feature of both $\mathrm{TiO}_{2}$ and $\mathrm{Ni}$ in the obtained composites. Internal morphology of prepared nanofibers and microparticles containing Ni NPs was characterized by TEM, which demonstrated characteristic structures with good dispersion of Ni NPs. In addition, the prepared structures were studied as a model for hydrogen production applications. The catalytic activity of the prepared materials was studied by in situ hydrolysis of $\mathrm{NaBH}_{4}$, which indicated that the nanofibers containing Ni NPs can lead to produce higher amounts of hydrogen when compared to other microparticles, also reported in this paper. Overall, these results confirm the potential use of these materials in hydrogen production systems.
\end{abstract}

\section{Introduction}

In recent years, due to concerns about global warming and the depletion of fossil fuels from the natural reservoirs, the utilization of various other sources of energy had been intensively investigated by scientific society. There are various means of obtaining energy from the natural and artificial resources. Among the various forms of energy, hydrogen has become one of the most promising future energy means of harvesting. However, the production of this important source by direct water splitting without any byproducts is one of potential alternatives to hydrogen fuel for future energy supply $[1,2]$. In order to overcome this rising demand for hydrogen, many methods have been devised, such as reforming of natural gas [3, 4], coal gasification [5], biomass pyrolysis and gasification [6], hydrolysis of chemical hydrides $[7,8]$, and electrolytic or photocatalytic water splitting $[1,2]$. Although the hydrogen production by water splitting using electrolysis of alkaline solution is commercially done, the efficiency of the process is low. However, efficiencies are increased through the use of polymer electrolyte membranes and photovoltaic reactions. Recently, there has been a growing interest in hydrogen generation and storage using metal hydrides, such as lithium hydride ( $\mathrm{LiH})$ [9], sodium 
aluminum hydride $\left(\mathrm{NaAlH}_{4}\right)$ [10], lithium borohydride $\left(\mathrm{LiBH}_{4}\right)$ [11], and sodium borohydride $\left(\mathrm{NaBH}_{4}\right)$ [12-14]. $\mathrm{NaBH}_{4}$ is the most favorable compound for hydrogen production because of its high hydrogen density, stability in alkaline solution [15], pure hydrogen generation [16], and recycling of the byproducts [17]. The governing reaction for hydrogen storage and generation is given as

$$
\mathrm{NaBH}_{4}+2 \mathrm{H}_{2} \mathrm{O} \longrightarrow \mathrm{NaBO}_{2}+2 \mathrm{H}_{2} \Delta \mathrm{H}=300 \mathrm{KJ} / \mathrm{mol} \text {. }
$$

Similarly, the strategies to use the metal-catalyst in presence of $\mathrm{NaBH}_{4}$ for accelerating the rate of hydrogen production had recently been accomplished. These various metal-catalysts include the platinum $(\mathrm{Pt})[18]$, palladium (Pd) [19], ruthenium $(\mathrm{Ru})[20]$, cobalt $(\mathrm{Co})[21]$, Co-B [22], nickel (Ni) [23], Ni-B [13], Ni-Co-B [24], and carbon nanotubes (CNT) [25] had been extensively utilized for the hydrogen production. Nickel metal is considered economically promising compared with other catalyst-forms especially with that of platinum. This is the reason the use of nickel-based catalysts had been evaluated for the production of hydrogen $[23,24]$. It is noteworthy to mention that $\mathrm{Ni}$ metal in the form of nanoparticulate in pure or associated form can be effectually used to boost the production of hydrogen when we used $\mathrm{NaBH}_{4}[23,24]$. Having these essential properties, we have selected nickel nanoparticles and $\mathrm{NaBH}_{4}$ as model catalyst for hydrogen production for the present study.

The electrospinning technique has attracted considerable attention due to the production of fibers with diameters that range from the micrometer to the nanometer size $[26,27]$. In a typical electrospinning process, an electrostatically driven polymer jet is ejected from a polymer solution or a sol-gel which undergoes a bending instability wherein the solvent evaporates, and an ultrafine stretched fiber is deposited on a grounded collector [28]. Consequently, the nanofibers obtained by this technique possess large surface areas when compared to other nanoparticle forms [29].

The present work presents the fabrication of various kinds of nanocatalysts forms and their capability to produce hydrogen. The fabricated nanoforms were fabricated as pure $\mathrm{TiO}_{2}$ nanofibers, modified $\mathrm{TiO}_{2}$ nanofibers containing $\mathrm{Ni}$ nanoparticles (NPs) and $\mathrm{TiO}_{2}$ microparticles containing $\mathrm{Ni}$ NPs. These prepared nanocatalysts have been intensively studied and well characterized with various states of the art techniques. After characterization, the efficiency of these materials was tested for the production of hydrogen through in situ hydrolysis of $\mathrm{NaBH}_{4}$.

\section{Experimental Section}

2.1. Materials. Poly(vinyl acetate) (PVAc, $\mathrm{Mw}=$ $500,000 \mathrm{~g} / \mathrm{mol}$ ) was obtained from Sigma Aldrich, USA. Titanium (IV) isopropoxide [Ti(Iso)], 98\% assay was purchased from Junsei Co. Ltd., Japan. Nickel nanopowder $<100 \mathrm{~nm}$, 99.9\% pure was purchased from Aldrich, USA. N,N-dimethylformamide (DMF) was obtained from Showa Chemicals Ltd., Japan and used without further purification.
2.2. Characterization. The morphology of the obtained nanocatalysts was analyzed utilizing a JEOL JSM-5900 scanning electron microscope, JEOL Ltd., Japan. The phase and crystallinity of the nanofibers and microparticles was investigated using an X-ray diffractometer (XRD, Rigaku Co., Japan) with $\mathrm{Cu} \mathrm{K} \alpha(\lambda=1.540 \AA)$ radiation over a Bragg angle ranging from 20 to $80^{\circ}$. Transmission electron microscopy (TEM) was done with a JEOL JEM 2010 operating at $200 \mathrm{kV}$, JEOL Ltd., Japan.

\subsection{Procedure}

2.3.1. Fabrication of Nanofibers by Electrospinning. The electrospinning process was utilized to produce $\mathrm{TiO}_{2}$ nanofibers containing Ni NPs. Typically, a sol-gel was prepared by mixing Ti(Iso) and PVAc (20 wt \%, in DMF) with a weight ratio of $2: 3$. Thereafter, a few drops of acetic acid were added until the solution became transparent under stirring. To fabricate the sol-gels containing Ni NPs, a step by step methodology was adopted. Briefly, $0.5 \mathrm{~g}$ of nickel NPs, were added into a previously prepared transparent solution of $\mathrm{Ti}$ (Iso)/PVAc; the solution was subsequently homogenized under stirring for 10 minutes. A high voltage power supply (CPS-60 K02V1, Chungpa EMT Co., Republic of Korea), capable of generating voltages up to $60 \mathrm{kV}$, was used for electrospinning the sol-gels. The solution to be electrospun was supplied through a plastic syringe attached to a capillary tip, which contained a copper pin to connect to the positive electrode (anode) in the high power supply. The electrospinning system was completed through the attachment of the negative electrode (cathode) to a grounded metallic collector. The nanofibers were deposited on rectangular collector covered with thin sheet of aluminum foil, equipped with heating system having temperature of $40^{\circ} \mathrm{C}$, which helps to remove the residual solvents after the fiber lands on collector (Scheme 1). The solutions were electrospun at $15 \mathrm{kV}$ and $15 \mathrm{~cm}$ working distance (the distance between the needle tip and the collector). The as-spun fibers were initially dried for $24 \mathrm{~h}$ at $80^{\circ} \mathrm{C}$ under vacuum in the presence of $\mathrm{P}_{2} \mathrm{O}_{5}$, to remove the remaining residual solvents. In order to remove the polymer used in making sol-gels, the samples were additionally heated in air atmosphere at $600^{\circ} \mathrm{C}$ for $1 \mathrm{~h}$ with heating rate of $5^{\circ} \mathrm{C} / \mathrm{min}$.

2.3.2. Fabrication of Microparticles by Sintering. A sol-gel was prepared by mixing $\mathrm{Ti}$ (Iso) and PVAc (20 wt $\%$ in DMF) with a weight ratio of $2: 3$, respectively. Thereafter, a few drops of concentrated acetic acid were added under stirring to afford a transparent solution, to which $0.5 \mathrm{~g}$ of nickel NPs were added. Hereafter, these solutions were homogeneously mixed under stirring for 10 minutes. However, instead of electrospinning as previously described for fabrication of nanofibers, this solution was dried under vacuum at $80^{\circ} \mathrm{C}$ for $48 \mathrm{~h}$ to completely remove the solvents. The obtained solid materials were finely ground and sintered in air at $600^{\circ} \mathrm{C}$ for $1 \mathrm{~h}$ with a heating rate of $5^{\circ} \mathrm{C} / \mathrm{min}$. After the sintering process, the samples were further subjected to fine grinding to additionally reduce their size. 


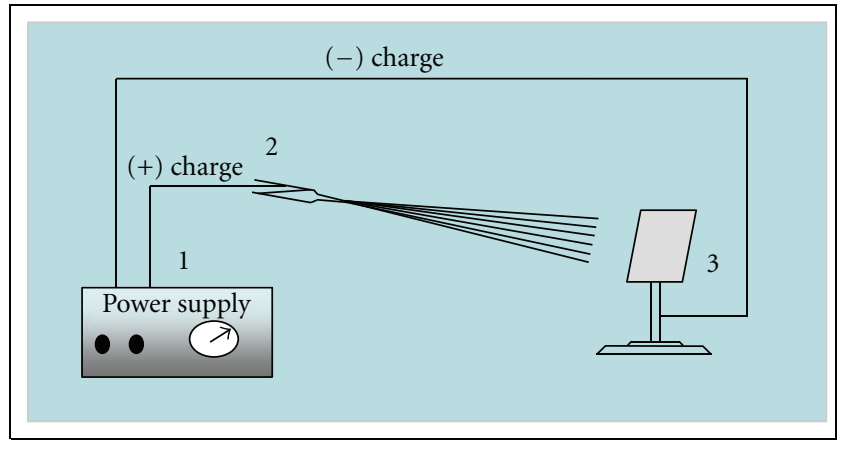

Scheme 1: The schematic illustration of a simple electrospinning spinning apparatus: (1) dc power supply (2) syringe, and (3) collector.

2.3.3. Hydrogen Production Studies. All the samples were investigated for their catalytic activity for the in situ hydrolysis of $\mathrm{NaBH}_{4}$. Typically, $50 \mathrm{mg}$ of all the sample combinations were placed in a specially designed tight sealed flask which contained $50 \mathrm{~mL}$ of a distill water containing $50 \mathrm{mg}$ of $\mathrm{NaBH}_{4}$ at constant temperature $\left(25^{\circ} \mathrm{C}\right)$. The catalytic performances were compared for the hydrogen production from hydrolysis of $\mathrm{NaBH}_{4}$. Briefly, the reaction proceeded at a stirring rate of $(1000 \mathrm{rpm})$ and the amount of hydrogen generated over time was measured immediately after all the components were added through the water displacement method [30], where the volume of hydrogen is equal to that of the displaced water whose weight was recorded by a balance. The balance connected with a computer, which was installed with the software of "Balance Talk", can read the weight of balance automatically.

\section{Results and Discussions}

In these experiments, PVAc was used as a binder for making the sol-gels to get good viscous solutions, so as to have the appropriate bending instability during the electrospinning process. After getting the nanofiber mats from electrospinning of the sol-gels, the obtained nanofiber mats were dried, and further subjected to frying in a furnace to remove the polymer binder (i.e., PVAc). In this context, (Figure 1(a)) shows the SEM images of nanofibers obtained after performing the frying process. As shown in this figure, the morphology of pristine nanofibers (after calcination) consists of pure $\mathrm{TiO}_{2}$ and is not affected by the high temperature heating. According to the high temperature of calcination used at $600^{\circ} \mathrm{C}$, which is twice the thermal degradation temperature of PVAc [31], this temperature should have been sufficient to remove the PVAc completely, leaving behind only ceramic $\mathrm{TiO}_{2}$. As can be observed in this image, that nanofiber morphology is in accordance with our previously established reports [32]. Furthermore, this image allows us to determine the average diameters of obtained nanostructures by using (Photoshop 6), around (10-12 individual diameters were measured per sample). The resultant diameters in case of pure $\mathrm{TiO}_{2}$ nanofiber were to be $600 \pm 320 \mathrm{~nm}$.
Figure 1(b) shows the SEM morphology of the nanofibers containing Ni NPs. It is observed that the morphology of the nanofibers was not affected by the addition of the Ni NPs, if the nanofibrous morphology is considered. However, an important observation was observed that nanofibers containing Ni presented a smaller diameter than the pristine $\mathrm{TiO}_{2}$ nanofibers. Moreover, the average fiber diameter calculated was to be $982 \pm 391 \mathrm{~nm}$ for nanofibers containing Ni NPs, which is comparatively less than $(600 \pm 320 \mathrm{~nm})$ as that was seen in case of pristine $\mathrm{TiO}_{2}$ nanofibers. It is likely that the colloidal solutions used for electrospinning were highly conductive after addition of $\mathrm{Ni}$, thus promoting a reduction in the fiber diameter [33]. A schematic representation for the fabrication of nanofibers is produced in (Scheme 2). Briefly, the first step of this scheme includes the preparation of a sol-gel containing Ni NPs. After this step, the prepared sol-gel is electrospun and calcinated to remove the binder (PVAc). The final step results in the formation of $\mathrm{TiO}_{2}$ nanofibers containing Ni NPs.

SEM results of the $\mathrm{TiO}_{2}$ microparticles containing $\mathrm{Ni}$ NPs are shown in (Figure 1(c)). It is observed that spherical particles are predominately present with wide range of diameters. The occurrence of particles appears in the form of clusters with the average diameters of $(7000 \pm 3607 \mathrm{~nm})$. To verify the addition of Ni nanoparticles into the nanofibers and microparticles, SEM-EDX analysis was performed on the obtained structures (Figure 2). As shown in (Figure 2(a)) and its corresponding EDX data from the area analyses of the nanofiber, the presence of Ti from this image clearly corresponds to the occurrence of pristine $\mathrm{TiO}_{2}$ nanofibers. The EDX data of its counterpart which contains certain amount of $\mathrm{Ni}$ in the nanofibers is also present in (Figure 2(b)). From this figure we can clearly find, that in addition to the peaks of $\mathrm{Ti}$, there is obvious presence of $\mathrm{Ni}$ peaks. This spectrum clearly demonstrates that small-sized NPs can be embedded in the nanofibres. Besides, this it can be clearly seen that diameter of these nanofibers containing $\mathrm{Ni}$ NPs is comparatively less than the pristine nanofibers (i.e., Figure 2(a)). This observation about the SEM-EDX results corroborates the simple SEM (Figures 1(a) and 2(b)) results, which elucidate the decrease in size of nanofibers after the addition of conductive Ni NPs. The EDX data originating from the $\mathrm{TiO}_{2}$ microparticles containing Ni NPs is presented in (Figure 2(c)). In this figure, the peaks corresponding to the $\mathrm{TiO}_{2}$ and $\mathrm{Ni}$ are present.

It is well known, that TEM can be utilized to differentiate between two different materials in regards to their different crystalline patterns. Therefore, to investigate the crystalline features of the prepared materials, TEM images were obtained and presented in (Figure 3). Figure 3(a) shows the results from pure $\mathrm{TiO}_{2}$ nanofibers, where it can be seen that the morphology of individual nanofibers is consistent with that of the defect-free morphology obtained from SEM images (Figure 1(a)). The high resolution transmission electron microscope (HR-TEM) image of the pristine nanofibers is presented in (Figure 3(b)). The portion indicated by arrow in the HR-TEM image indicates that there is no dislocation of the crystal lattice and the crystal planes are arranged in a linearly unique pattern consistent of pure $\mathrm{TiO}_{2}$ [34]. 


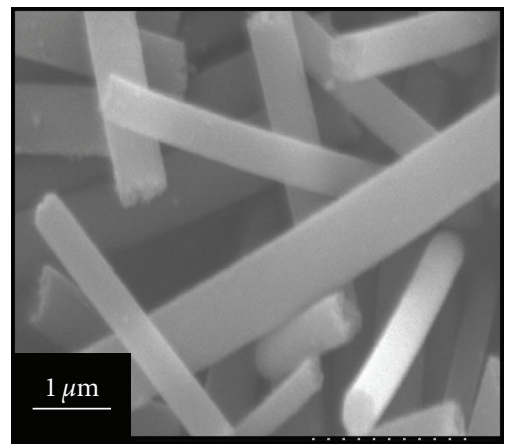

(a)

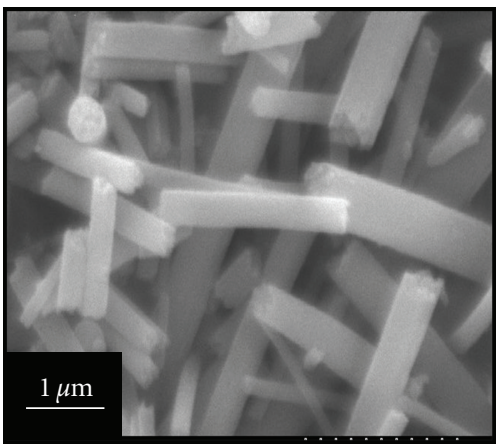

(b)

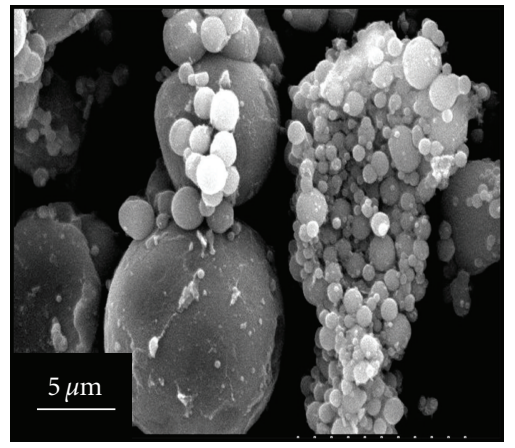

(c)

FIgURE 1: SEM images of the obtained catalysts after the calcinations process. Images of the pristine $\mathrm{TiO}_{2}$ nanofibers (a), images of the TiO nanofibers containing $\mathrm{Ni} \mathrm{NPs}(\mathrm{b})$, and $\mathrm{TiO}_{2}$ microparticles containing Ni NPs (c).

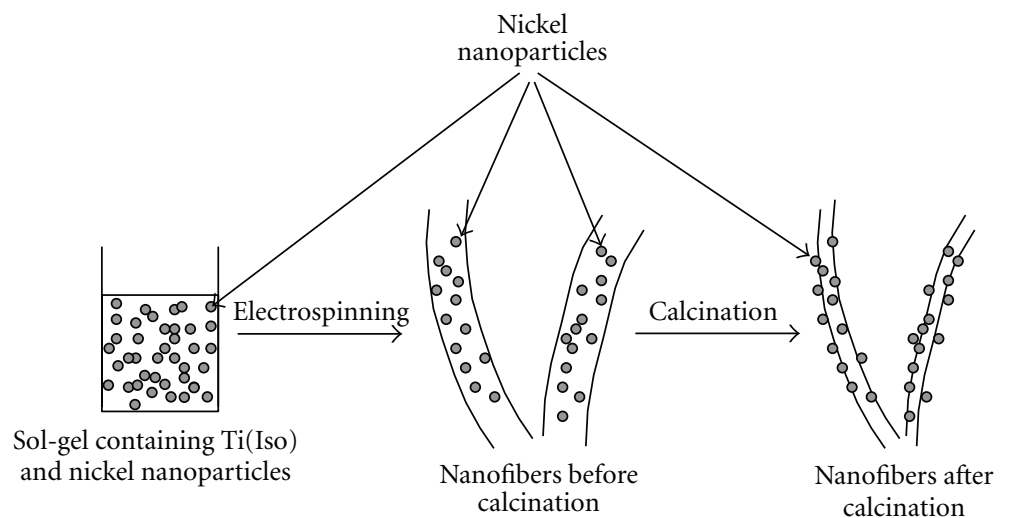

Scheme 2: Representation of this novel strategy to fabricate $\mathrm{TiO}_{2}$ nanofibers containing Ni NPs.

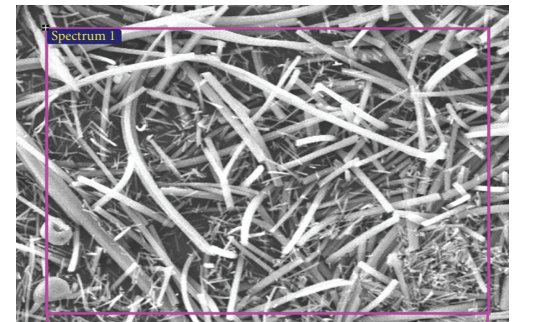

$600 \mu \mathrm{m}$

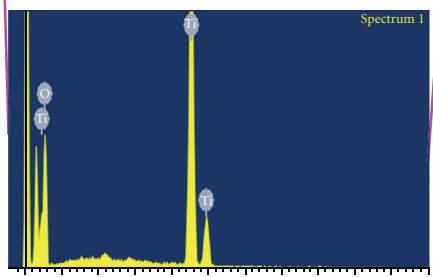

$\begin{array}{llllllllllll}0 & 1 & 2 & 3 & 4 & 5 & 6 & 7 & 8 & 9 & 10 & 11\end{array}$ $(\mathrm{keV})$

(a)

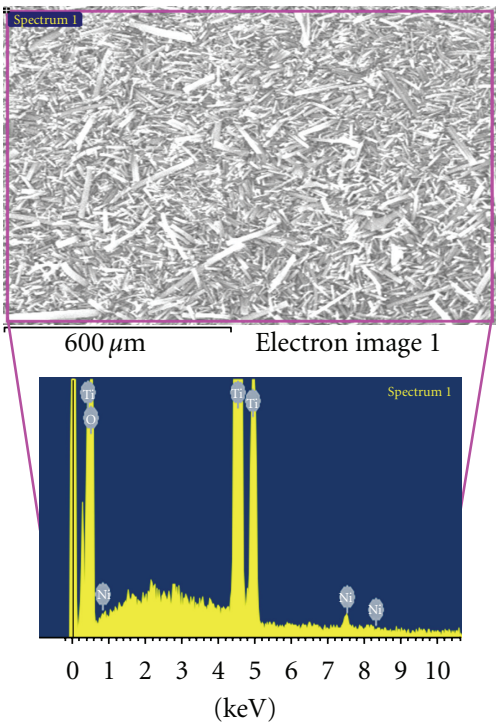

(b)

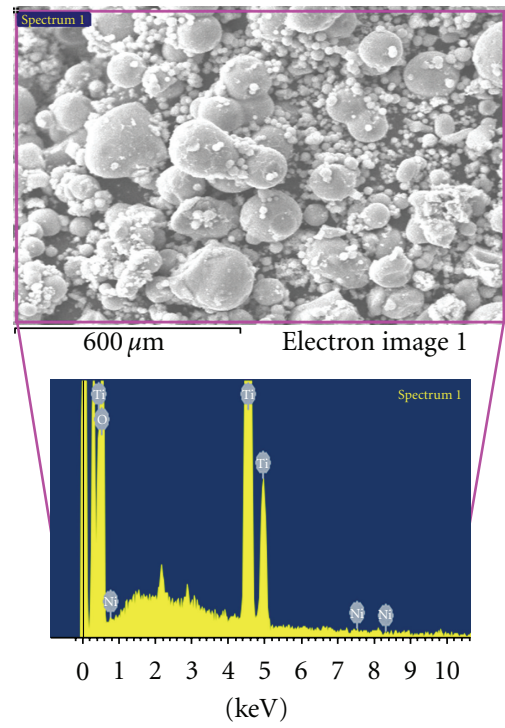

(c)

FIgURE 2: SEM images with EDX analysis. The EDX area of the pristine $\mathrm{TiO}_{2}$ nanofibers and its corresponding data (a), the EDX area of the modified $\mathrm{TiO}_{2}$ nanofibers containing Ni NPs and its corresponding data (b), the EDX area of the modified TiO ${ }_{2}$ microparticles containing Ni NPs and its corresponding data (c). 


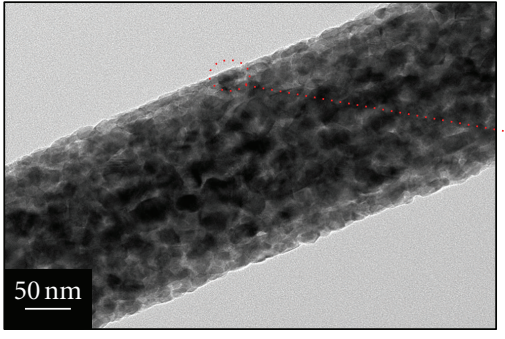

(a)

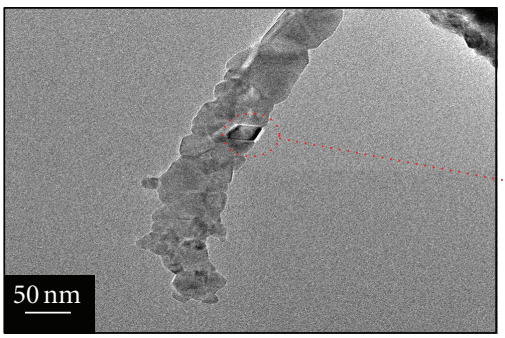

(c)

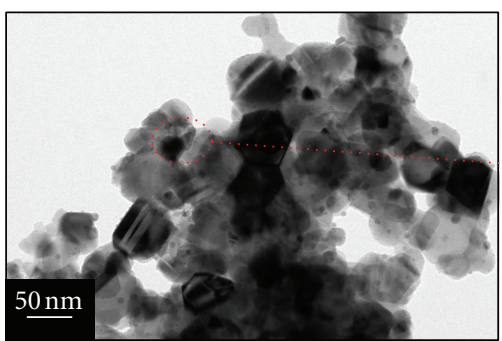

(e)

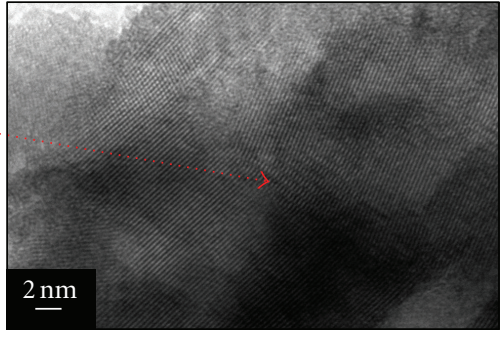

(b)

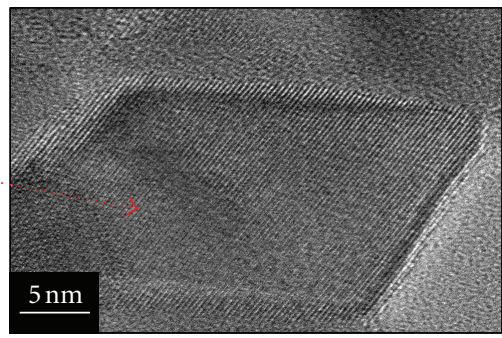

(d)

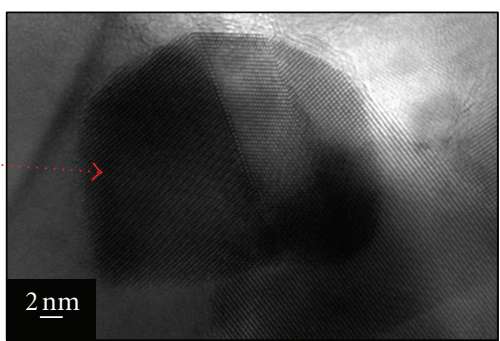

(f)

FIGURE 3: TEM images of nanofibers and microparticles after calcination process. Pristine $\mathrm{TiO}_{2}$ nanofibers in low magnification (a), the HRTEM images of the former figure (b). The low magnification images of the $\mathrm{TiO}_{2}$ nanofibers containing Ni NPs (c), the HR-TEM images of the corresponding former figure. The low magnification images of the $\mathrm{TiO}_{2}$ microparticles containing Ni NPs (e), the HR-TEM images of the corresponding figure (f).

Figure 3(c) presents TEM images of the nanofibers containing Ni NPs at low magnification, where it is confirmed that the nanoparticles are present on the nanofiber surfaces. These Ni NPs can be seen as darker areas than the main $\mathrm{TiO}_{2}$ nanofiber, as indicated by the arrows. HRTEM images of the marked areas in (Figure 3(c)) are presented in (Figure 3(d)). Overall, these images reveal the expected cubic shape for the Ni NPs, with diameters from 15 to $20 \mathrm{~nm}$, is present. (Figure 3(e)) represents the low magnification TEM image of the microparticles containing Ni NPs. The arrow originating from encircled area shows the HR-TEM of the Ni NPs in (Figure 3(f)). It can be clearly seen, that Ni NPs are well associated with $\mathrm{TiO}_{2}$ microparticles. In these figures, it can be seen that crystals have good atomic arrangement with respect to two components. The atoms can be seen as uniformly arranged having regular and periodic behavior indicating individual $\mathrm{TiO}_{2}$ and $\mathrm{Ni}$ components in them, which overall indicate good crystallinity of the synthesized structures. Therefore, one can come up to an interesting finding that the crystal patterns of the both components are arranged in a leaner format and are without the dislocations or imperfections in the lattice planes. It is noteworthy to mention that in case of SEM analyses the presence of Ni NPs in case of nanofibers and microparticles was not so obvious, rationale is due high intensity electron beam of TEM which can differentiate the internal as well as external contents of the crystalline materials, of which former one is incapable to do alone, due to its poor resolution.

As shown in (Figure 4), the spectra show the XRD pattern of pristine $\mathrm{TiO}_{2}$ nanofibers, $\mathrm{TiO}_{2}$ nanofibers containing $\mathrm{Ni}$ NPs, and $\mathrm{TiO}_{2}$ microparticles containing Ni NPs. In all of the materials obtained, there are strong diffraction peaks at $2 \theta$ values of $25.50,37.69,48.04,53.85,55.08,62.75$, and $79.98^{\circ}$, which correspond to the crystal planes (110), (401), (020), (601), (513), (403), and (621), respectively, and indicate the formation of pure anatase titanium dioxide [35]. Further, the $\mathrm{TiO}_{2}$ nanofibers containing $\mathrm{Ni}$ NPs and $\mathrm{TiO}_{2}$ microparticles containing Ni NPs presented the $\mathrm{TiO}_{2}$ peaks as well as the additional peaks attributed to $\mathrm{Ni}$ at $2 \theta$ values of $27.50,36.80$, $38.35,43.16,62.75,70.33$, and $79.98^{\circ}$ corresponding to the crystal planes (220), (311), (311), (312), and (322) [36], thus confirming the presence of the embedded Ni NPs. It is interesting to note that the intensities of the Ni peaks in these composites were the same, which to some extent is expected, since the metal concentrations used were the same. 


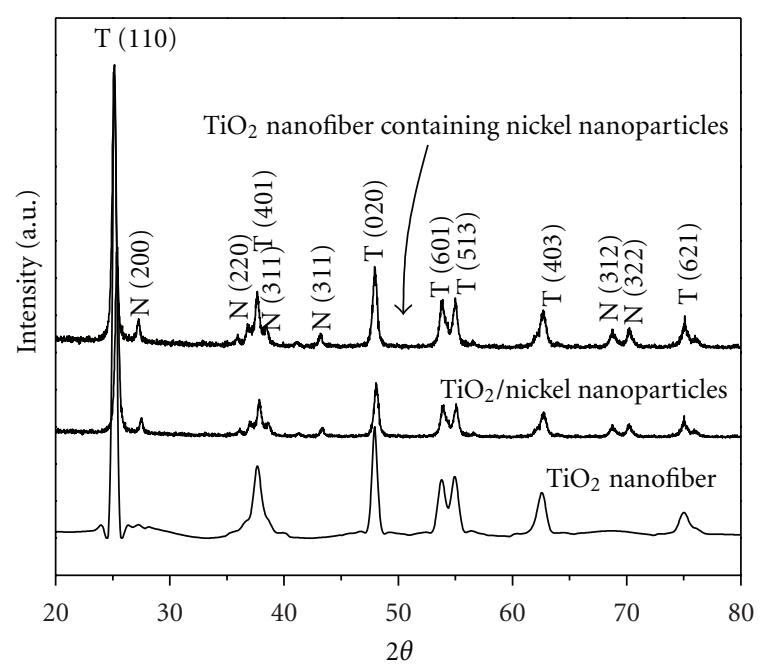

FIGURE 4: XRD results of the different nanocomposites.

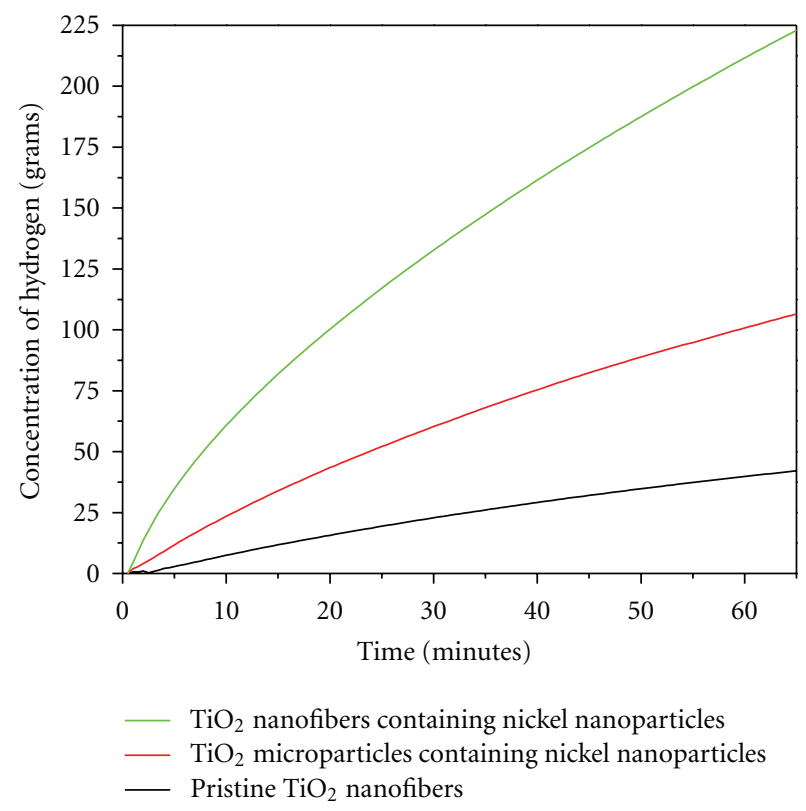

FIGURE 5: Hydrogen production of the by various nanocomposites at $26^{\circ} \mathrm{C}$ in $\mathrm{pH} 7.4$ distilled water to demonstrate the highest hydrogen production.

Figure 5 shows the results obtained after using these synthesized structures as nanocatalysts for hydrogen production. These results demonstrate the capability of all prepared catalyst combination render to produce different amounts of hydrogen. Overall, the hydrogen production was in the range of 25 to 250 grams depending upon the nanocatalyst investigated. In more details, it is observed that the highest amount of hydrogen production is shown by the $\mathrm{TiO}_{2}$ nanofibers containing Ni NPs, followed by $\mathrm{TiO}_{2}$ microparticles containing Ni NPs, and finally by the pristine nanofibers. The main reason for the higher amount of hydrogen production from the first two nanocatalysts is clearly attributed due to the presence of Ni NPs [13].
The amount of hydrogen produced by the pristine $\mathrm{TiO}_{2}$ nanofibers ( $\mathrm{Ni}$ free) is due to the presence of the original $\mathrm{NaHB}_{4}$ in the processing media (without catalyst). Moreover, the $\mathrm{TiO}_{2}$ nanofibers containing $\mathrm{Ni}$ NPs produce more hydrogen than its $\mathrm{TiO}_{2}$ microparticle containing Ni NPs analog. It is proposed that the higher surface to volume ratio present in the nanofibers is responsible for this effect [29].

To practically investigate that nanofibers do have higher surface to volume ratio than that of microparticles, which in turn can put more light, the surface area of both fibers and microparticles has been measured by using BrunauerEmmett-Teller (BET) technique (ASAP 2010, Micromeritics, Norcross, GA). It is noteworthy to mention that exact amount of $0.5 \mathrm{~g}$ of Ni NP was used to mix with sol-gel to fabricate nanofibers and microparticles, therefore one would assume that two combinations would produce same results. However, from those tests, it was observed that microparticles containing Ni NPs had surface area of 13.6765 $\pm 0.675 \mathrm{~m}^{2} / \mathrm{g}$. The pure $\mathrm{TiO}_{2}$ nanofibers had a surface area of $15.3456 \pm 0.1751 \mathrm{~m}^{2} / \mathrm{g}$, and the nanofibers containing $\mathrm{Ni}$ NPs had a surface area of $23.2782 \pm 0.1961 \mathrm{~m}^{2} / \mathrm{g}$, respectively. These results are in accordance with our previous reports [29]. Overall, these numbers indicate that nanofibers with $\mathrm{Ni}$ had much higher surface area, followed by pure $\mathrm{TiO}_{2}$ nanofibers and $\mathrm{TiO}_{2}$ microparticles containing Ni NPs. Furthermore, this higher surface to volume ratio in case of $\mathrm{TiO}_{2}$ nanofibers containing Ni NPs self explains the reason for more hydrogen production than the other two combinations.

\section{Conclusion}

In conclusion, we were able to fabricate three different types of nanomaterials through combination of sol-gel and electrospinning process. Electrospinning of a colloid comprised of $\mathrm{Ti}$ (Iso) and Ni NPs produced ceramic nanofibers that contained attached Ni NPs and partially captured NPs. The SEM instrument was used to find out the morphologies of nanomaterials after the electrospinning and calcinations of sol-gel. SEM equipped with EDX technique was used to differentiate between pristine and Ni-loaded nanofibers and microparticles composites. TEM images were used to determine the appearance of Ni NPs over the individual nanofibers. All the materials obtained were evaluated for their catalytic activity towards hydrogen production, resulting in the nanofibers containing Ni NPs being the most promising materials for this application was due to high surface to volume ratio of nanofibers containing Ni NPs resulted to produce the highest production of hydrogen.

\section{Acknowledgments}

This work was supported by Priority Research Center Program through the National Research Foundation of Korea (NRF) funded by the Ministry of Education, Science and Technology (2012-0006693). F. A. Sheikh and J. Macossay are thankful for partial financial support for this work from NIH-NIGMS-NIA Grant no. 1SC2AG036825-01. 


\section{References}

[1] H. de Battista, R. J. Mantz, and F. Garelli, "Power conditioning for a wind-hydrogen energy system," Journal of Power Sources, vol. 155, no. 2, pp. 478-486, 2006.

[2] H. Miland, R. Glöckner, P. Taylor, R. Jarle Aaberg, and G. Hagen, "Load control of a wind-hydrogen stand-alone power system," International Journal of Hydrogen Energy, vol. 31, no. 9, pp. 1215-1235, 2006.

[3] R. J. Farrauto, "Introduction to solid polymer membrane fuel cells and reforming natural gas for production of hydrogen," Applied Catalysis B, vol. 56, no. 1-2, pp. 3-7, 2005.

[4] A. Heinzel, B. Vogel, and P. Hübner, "Reforming of natural gas-hydrogen generation for small scale stationary fuel cell systems," Journal of Power Sources, vol. 105, no. 2, pp. 202-207, 2002.

[5] G. J. Stiegel and M. Ramezan, "Hydrogen from coal gasification: an economical pathway to a sustainable energy future," International Journal of Coal Geology, vol. 65, no. 3-4, pp. 173190, 2006.

[6] E. E. Iojoiu, M. E. Domine, T. Davidian, N. Guilhaume, and C. Mirodatos, "Hydrogen production by sequential cracking of biomass-derived pyrolysis oil over noble metal catalysts supported on ceria-zirconia," Applied Catalysis A, vol. 323, pp. 147-161, 2007.

[7] S. C. Amendola, S. L. Sharp-Goldman, M. S. Janjua et al., "Safe, portable, hydrogen gas generator using aqueous borohydride solution and Ru catalyst," International Journal of Hydrogen Energy, vol. 25, no. 10, pp. 969-975, 2000.

[8] J. H. Kim, K. T. Kim, Y. M. Kang et al., "Study on degradation of filamentary Ni catalyst on hydrolysis of sodium borohydride," Journal of Alloys and Compounds, vol. 379, no. 1-2, pp. 222-227, 2004.

[9] J. J. Vajo, S. L. Skeith, F. Mertens, and S. W. Jorgensen, "Hydrogen-generating solid-state hydride/hydroxide reactions," Journal of Alloys and Compounds, vol. 390, no. 1-2, pp. 55-61, 2005.

[10] J. O. Jensen, Q. Li, R. He, C. Pan, and N. J. Bjerrum, "100$200{ }^{\circ} \mathrm{C}$ polymer fuel cells for use with $\mathrm{NaAlH}_{4}$," Journal of Alloys and Compounds, vol. 404-406, pp. 653-656, 2005.

[11] Y. Kojima, K. I. Suzuki, and Y. Kawai, "Hydrogen generation from lithium borohydride solution over nano-sized platinum dispersed on $\mathrm{LiCoO}_{2}$," Journal of Power Sources, vol. 155, no. 2, pp. 325-328, 2006.

[12] H. I. Schlesinger, H. C. Brown, A. E. Finholt, J. R. Gilbreath, H. R. Hoekstra, and E. K. Hyde, "Sodium borohydride, its hydrolysis and its use as a reducing agent and in the generation of hydrogen," Journal of the American Chemical Society, vol. 75, no. 1, pp. 215-219, 1953.

[13] D. Hua, Y. Hanxi, A. Xinping, and C. Chuansin, "Hydrogen production from catalytic hydrolysis of sodium borohydride solution using nickel boride catalyst," International Journal of Hydrogen Energy, vol. 28, no. 10, pp. 1095-1100, 2003.

[14] M. Zahmakiran and S. Özkar, "Water dispersible acetate stabilized ruthenium(0) nanoclusters as catalyst for hydrogen generation from the hydrolysis of sodium borohyride," Journal of Molecular Catalysis A, vol. 258, no. 1-2, pp. 95-103, 2006.

[15] J. A. Ritter, A. D. Ebner, J. Wang, and R. Zidan, "Implementing a hydrogen economy," Materials Today, vol. 6, no. 9, pp. 18-23, 2003.

[16] J. H. Kim, H. Lee, S. C. Han, H. S. Kim, M. S. Song, and J. Y. Lee, "Production of hydrogen from sodium borohydride in alkaline solution: development of catalyst with high performance," International Journal of Hydrogen Energy, vol. 29, no. 3, pp. 263-267, 2004.
[17] D. L. Calabretta and B. R. Davis, "Investigation of the anhydrous molten $\mathrm{Na}-\mathrm{B}-\mathrm{O}-\mathrm{H}$ system and the concept: electrolytic hydriding of sodium boron oxide species," Journal of Power Sources, vol. 164, no. 2, pp. 782-791, 2007.

[18] Y. Kojima, K. I. Suzuki, K. Fukumoto et al., "Development of $10 \mathrm{~kW}$-scale hydrogen generator using chemical hydride," Journal of Power Sources, vol. 125, no. 1, pp. 22-26, 2004.

[19] N. Patel, B. Patton, C. Zanchetta et al., "Pd-C powder and thin film catalysts for hydrogen production by hydrolysis of sodium borohydride," International Journal of Hydrogen Energy, vol. 33, no. 1, pp. 287-292, 2008.

[20] J. S. Zhang, W. N. Delgass, T. S. Fisher, and J. P. Gore, "Kinetics of Ru-catalyzed sodium borohydride hydrolysis," Journal of Power Sources, vol. 164, no. 2, pp. 772-781, 2007.

[21] W. Ye, H. Zhang, D. Xu, L. Ma, and B. Yi, "Hydrogen generation utilizing alkaline sodium borohydride solution and supported cobalt catalyst," Journal of Power Sources, vol. 164, no. 2, pp. 544-548, 2007.

[22] S. U. Jeong, R. K. Kim, E. A. Cho et al., "A study on hydrogen generation from $\mathrm{NaBH}_{4}$ solution using the high-performance Co-B catalyst," Journal of Power Sources, vol. 144, no. 1, pp. 129-134, 2005.

[23] O. Metin and S. Özkar, "Hydrogen generation from the hydrolysis of sodium borohydride by using water dispersible, hydrogenphosphate-stabilized nickel $(0)$ nanoclusters as catalyst," International Journal of Hydrogen Energy, vol. 32, no. 12, pp. 1707-1715, 2007.

[24] J. C. Ingersoll, N. Mani, J. C. Thenmozhiyal, and A. Muthaiah, "Catalytic hydrolysis of sodium borohydride by a novel nickelcobalt-boride catalyst," Journal of Power Sources, vol. 173, no. 1, pp. 450-457, 2007.

[25] R. Peña-Alonso, A. Sicurelli, E. Callone, G. Carturan, and R. Raj, "A picoscale catalyst for hydrogen generation from $\mathrm{NaBH}_{4}$ for fuel cells," Journal of Power Sources, vol. 165, no. 1, pp. 315323, 2007.

[26] M. Ziabari, V. Mottaghitalab, and A. K. Haghi, "A new approach for optimization of electrospun nanofiber formation process," Korean Journal of Chemical Engineering, vol. 27, no. 1, pp. 340-354, 2010.

[27] G. T. Kim, Y. C. Ahn, and J. K. Lee, "Characteristics of Nylon 6 nanofilter for removing ultra fine particles," Korean Journal of Chemical Engineering, vol. 25, no. 2, pp. 368-372, 2008.

[28] F. A. Sheikh, N. A. M. Barakat, M. A. Kanjwal, S. J. Park, D. K. Park, and H. Y. Kim, "Synthesis of poly(vinyl alcohol) (PVA) nanofibers incorporating hydroxyapatite nanoparticles as future implant materials," Macromolecular Research, vol. 18, no. 1, pp. 59-66, 2010.

[29] M. A. Kanjwal, N. A. M. Barakat, F. A. Sheikh, W. I. Baek, M. S. Khil, and H. Y. Kim, "Effects of silver content and morphology on the catalytic activity of silver-grafted titanium oxide nanostructure," Fibers and Polymers, vol. 11, no. 5, pp. 700-709, 2010.

[30] Y. Chen and H. Kim, "Use of a nickel-boride-silica nanocomposite catalyst prepared by in-situ reduction for hydrogen production from hydrolysis of sodium borohydride," Fuel Processing Technology, vol. 89, no. 10, pp. 966-972, 2008.

[31] F. A. Sheikh, M. A. Kanjwal, H. Y. Kim, and H. Kim, "Fabrication of titanium dioxide nanofibers containing hydroxyapatite nanoparticles," Applied Surface Science, vol. 257, no. 1, pp. 296-301, 2010.

[32] F. A. Sheikh, N. A. M. Barakat, M. A. Kanjwal et al., "Electrospun titanium dioxide nanofibers containing hydroxyapatite and silver nanoparticles as future implant materials," Journal 
of Materials Science: Materials in Medicine, vol. 21, no. 9, pp. 2551-2559, 2010.

[33] F. A. Sheikh, N. A. M. Barakat, M. A. Kanjwal, S. H. Jeon, H. S. Kang, and H. Y. Kim, "Self synthesize of silver nanoparticles in/on polyurethane nanofibers: nano-biotechnological approach," Journal of Applied Polymer Science, vol. 115, no. 6, pp. 3189-3198, 2010.

[34] M. A. Kanjwal, N. A. M. Barakat, F. A. Sheikh, M. S. Khil, and H. Y. Kim, "Functionalization of electrospun titanium oxide nanofibers with silver nanoparticles: strongly effective photocatalyst," International Journal of Applied Ceramic Technology, vol. 7, no. 1, pp. E54-E63, 2010.

[35] JCDPS card no 21-1272.

[36] JCDPS card no 7440-02-0. 



The Scientific World Journal

Submit your manuscripts at

http://www.hindawi.com

\section{World Journal}

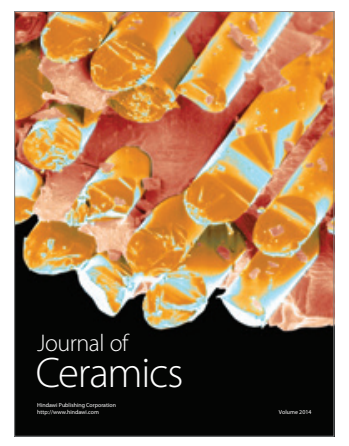

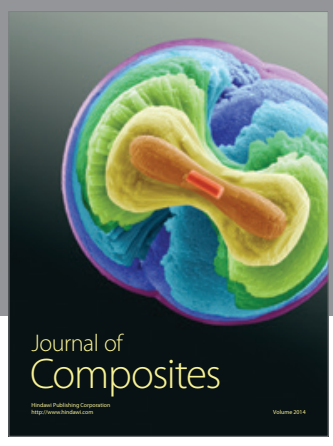
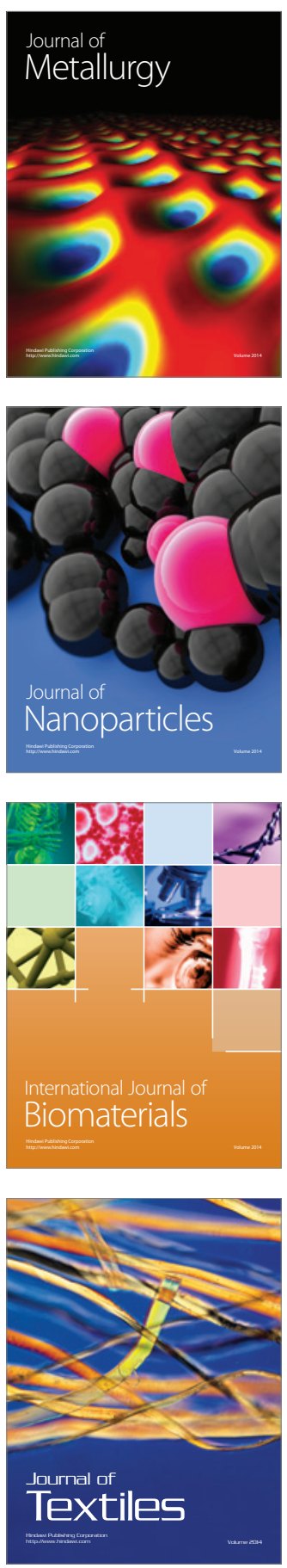